\title{
Gas Turbine Performance Adaptation using a Developed Search Algorithm
}

\author{
E.G. Saturday \\ University of Port Harcourt \\ Department of Mechanical Engineering \\ Choba, Port Harcourt, Nigeria
}

\author{
P. Nweke \\ University of Port Harcourt \\ Department of Mechanical Engineering \\ Choba, Port Harcourt, Nigeria
}

\begin{abstract}
This work focused on developing a technique for adaptation of gas turbine power plants. There are five basic losses or efficiency parameters in gas turbine operation which are compressor isentropic efficiency, turbine isentropic efficiency, combustor pressure loss, the exhaust pressure loss and the combustion efficiency. The performance of a gas turbine can be accurately simulated if these five parameters are known. The estimation of these parameters entails adapting the engine to the current operating conditions hence the process is known as adaptation. A sequential search algorithm and software were developed for the adaptation process. The software was developed in $\mathrm{C \#}$ programming environment. To ensure to the efficiency parameters estimated are accurate, the estimated efficiency parameters were then used to calculate the turbine exit temperature and the net work output using data from two gas turbine power plants. For both gas turbine power plants, the calculated (simulated) turbine exit temperature and the net work output from the developed software closely approximate those obtained from the field. The net power output values are closer with percentage difference between the simulated and field values as $0.009 \%$ and $0.005 \%$ for the two plants while the percentage difference between the field values and the simulated turbine exit temperature values are $0.803 \%$ and $0.184 \%$ for the two power plants. The efficiency parameters obtained in this work are more accurate compared to previous work where they were manually varied to compare field data and simulated values. The developed adaptation technique could be applied to any gas turbine running on the simple open cycle with one compressor and one turbine which is suitable for electrical power production.
\end{abstract}

\section{Keywords}

Adaptation, gas turbine, efficiency parameters, operating conditions

\section{INTRODUCTION}

The gas turbine engine has several applications including electrical power production. The simple cycle engine with one compressor, a combustion chamber (CC) and one turbine is widely used for electrical power production. Gas turbine operation is a business and the engine operators are concerned with its performance at different conditions. Performance analysis is carried out to determine the power out and the thermal efficiency. There are models for estimating the performance of the turbine engine. The accuracy of the performance parameters depends of the accuracy of the input data. Five basic losses or efficiency parameters could be identified in gas turbine operation. These include the isentropic efficiency of the compressor, the isentropic efficiency of the turbine, the combustor pressure loss, the exhaust pressure loss and the combustion efficiency [1]. Once these efficiency parameters are known, the engine performance parameters can be predicted accurately. Gas turbine adaptation is the accurate estimation of the relevant input parameters so that the simulated engine performance parameters from engine performance mathematical models will be the same as or closely matches those produced by the real engine in operation. Gas turbine adaptation in this sense is different from putting gas turbine into different uses as presented in a number of works [2 - 4]. The performance parameters depend on the input parameters. $\mathrm{Li}$ et al. [5] referred to the input parameters as to-be-adapted component parameters while the performance parameters are taken as target performance parameters. Temperatures and pressure values that will lead to the estimation of power output or thermal efficiency of the turbine are taken as target performance parameters which are dependent on the to-beadapted component parameters. The to-be-adapted component parameters which are referred to as independent parameters are usually air flow rate, pressure ratio and the efficiencies of the basic components. Adaptation can be done at the design point of the engine or at the off-design point.

Several works on gas turbine adaptation have been carried out. Stamatis et al. [6] presented a model that permits the simulation of turbine achievements with the feasibility of acclimating to engine peculiarities. Measurements were done along gas path, for adaptation to a specified performance model by suitable adjustment of the component performance maps. This method can deliver correct simulation for gas engines of similar type, but different in manufacture tolerances. Roth et al. [7] carried out performance adaption method at off-design situations, it was simulated and efficiency at design points matched. Such a design-point adaptation alongside matching was executed by carefully choosing a set of design-point component parameters. In this, the case differs for such engines with complex configurations due to inadequacy of part data. Roth et al. [8] further introduced cycle model matching for engines. The idea was tested in a modest substitute matching problem. However, more work needs to be carried out to exploit the idea in gas engines.

Li [9] used gas path determinations such as gas temperatures, pressures, shaft speeds and fuel flow rate, developed an Adaptive Gas Path Analysis (Adaptive GPA) technique to measure engine performance and gas component fitness status. The study reveals that the novel linear and nonlinear Adaptive GPA approaches can be useful to correctly estimate the ineffective engine performance and forecast the vitiation of key engine path components with the manifestation of measurement disturbance. Trying to boost the performance forecast precision of gas turbines at different off-design conditions, a non-linear manifold performance acclimation technique was carried out through genetic algorithm 
procedure [10]. Genetic algorithm helps in the enhancement of performance forecast accuracy of gas plant at various offdesign conditions by standardizing the engines performance model against existing test data. The authors applied the established off-design performance acclimation approach to model a spool turbo-shaft aero gas engine and they showed that there were significant boost in the performance model exactness at off-design working conditions.

Adaptation requires the availability of engine test data. Li et al [11] utilized aeroengine test-bed data in carrying out adaptation of an an aero engine. Genetic algorithm (GA) has been applied in adaptation of gas turbines [12] and GA has been applied together with the least squares method in gas turbine adaptation [13]. Sometimes, the gas turbine engine is adapted to transient performance of the engine using measurement data obtained under transient condition, and used as dynamic simulation model exploiting component performance maps [14]. In this, the coverage of the adaptation results is narrow compared to off-design performance adaptation. Using Engine performance test data, Kim et al. [15] utilized multi-island genetic algorithm (MIGA) optimization technique in gas turbine adaptation, calibrating compressor maps and applying the methodology to lowbypass ratio turbofan engine. The proposed methodology is aimed at having more accurate gas turbine performance results. In essence, adaptation is a perquisite for gas turbine performance analysis. The steady-state off-design performance of the gas turbine engine may be the focus in the adaptation process [16].

Softwares are usually employed to carry out adaptation. PYTHIA [17], Cranfield University in-house software is one of such tools - it can be used for both design point performance adaptation and off-design performance adaptation. In the present work, adaptation is applied to the simple cycle engine and the five efficiency parameters are taken as independent input parameters to be estimated. In addition to these parameters, the pressure ratio of the engine, the ambient temperature, and the air flow rate all act as input data. Also, the power output from the plant in the field and the turbine exit temperature are taken as two performance parameters of the plant in the field. In carrying out performance analysis of gas turbines, these parameters were arbitrarily selected in the gas turbine performance analysis software developed [1] and the performance results from the software were not too far off from those obtained from the field. Such a manual selection approach is time consuming and will not be as accurate as that presented here where software is developed to make several computations and select the optimum efficiency parameters.

\section{METHODOLOGY}

The five efficiency parameters are to be estimated in the adaptation process presented in this work. The net power output and the turbine exhaust gas temperature are two parameters that can be measured from the plant in the field. These two parameters can also be estimated with relevant input data and different values of the efficiency parameters. There must be mathematical relationships between the efficiency parameters and net power output plus the exhaust gas temperature. The differences between power output and the exhaust gas temperature from the field and those from the simulations should be minimal. The adaptation proposed in this research is to obtain the set of efficiency parameters where the differences between the target parameters (power output and exhaust gas temperature) obtained from the field and from simulations are minimal.

\subsection{The Net Power Output and Turbine Exit Temperature}

The net power output from the field is read from the plant in the field. In this study, two gas turbine power plants in Rivers state, Nigeria were used. Plant I is of power output $26 \mathrm{MW}$ while plant II is of power output $65 \mathrm{MW}$. Both plants are of the simple cycle basis. Further properties of the plants are presented later. A temperature-entropy (T-s) diagram and a block diagram of the simple cycle plant are shown in Figure 1. This will help in evaluating the net power output of the plant.
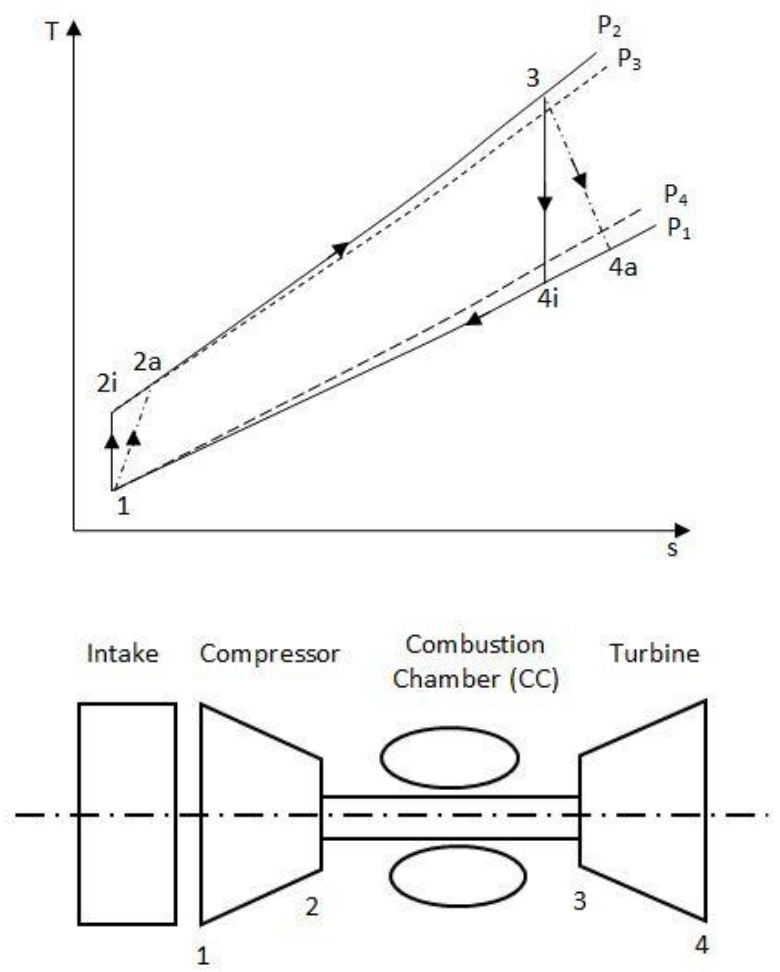

Fig 1: T-s and block diagrams of simple gas turbine engine cycle [18]

From the T-s diagram, the ideal and actual compression processes are 1-2i and 1-2a respectively, while the ideal and actual expansion processes are 3-4i and 3-4a respectively. There is pressure loss in CC and exhaust process, hence, $\mathrm{p}_{2}>$ $\mathrm{p}_{3}$ and $\mathrm{p}_{4}>\mathrm{p}_{1}$. The pressure ratio across the plant in the compression process is $r_{p}=p_{2} / p_{1}$ while the pressure ratio in the expansion process is $r_{p}{ }^{\prime}=p_{3} / p_{4}$. The net power output $\dot{W}_{n e t}$ is given by Equation (1),

$\dot{W}_{n e t}=\dot{W}_{t a}-\dot{W}_{c a}$

where $\dot{W}_{c a}$ is the actual work consumed by compressor and $\dot{W}_{t a}$ is the actual turbine work output. The compressor work output is given as,

$\dot{W}_{c a}=\dot{m}_{a} c_{p, a}\left(T_{2 a}-T_{1}\right)=\frac{\dot{W}_{c, i}}{\eta_{c i}}=\frac{\dot{m}_{a} c_{p, a}\left(T_{2 i}-T_{1}\right)}{\eta_{c, i}}$

where $\dot{W}_{c, i}, \dot{m}_{a}, c_{p, a}, \eta_{c i}, T_{2 i}$ and $T_{1}$ are the ideal compressor work, air flow rate, specific heat capacity of the, isentropic efficiency of the compression process, compressor 
exit temperature (ideal) and ambient temperature respectively. $T_{2 i}$ relates with the pressure ratio as,

$T_{2 i}=T_{1}\left(r_{p}\right)^{\frac{\gamma_{a}-1}{\gamma_{a}}}$

$\gamma_{a}$ is the ratio of specific heat capacities of air, taken as 1.4 in this work. $T_{2 a}$ and $T_{2 i}$ are related as,

$T_{2 a}=T_{1}+\frac{\left(T_{2 i}-T_{1}\right)}{\eta_{c i}}$

The turbine power output is expressed as,

$\dot{W}_{t a}=\dot{m}_{3} c_{p, g}\left(T_{3}-T_{4 a}\right)=\eta_{t, i} \dot{W}_{t, i}=\eta_{t i} \dot{m}_{3} c_{p, g}\left(T_{3}-T_{4 i}\right)$

where $\dot{W}_{t, i}, \dot{m}_{3}, c_{p, g}, \eta_{t i}, T_{3}$ and $T_{4 i}$ are the ideal turbine work output, mass flow rate of the flue gases at the turbine inlet, specific heat capacity of the flue gases, isentropic efficiency of expansion process, the turbine entry temperature and the ideal temperature at the turbine exit. $\dot{m}_{3}$ is taken to be same as $\dot{m}_{a}$ in this work by assuming that the fuel flow rate is the same as air extracted for blade cooling. An approximate value of specific heat capacity of the flue gases is obtained by exploiting the mass fractions of the air and the fuel in the combustion process.. The turbine entry temperature is obtained by carrying out energy balance in the $\mathrm{CC}$, and it is given as [19],

$T_{3}=\frac{\dot{m}_{a} c_{p, a} T_{2 a}+\dot{m}_{f} L C V_{f} \eta_{c c}}{\left(\dot{m}_{a}+\dot{m}_{f}\right) c_{p, f}}$

where $\dot{m}_{f}, c_{p, f}, L C V_{f}$ and $\eta_{c c}$ are fuel flow rate, specific heat capacity of the fuel, the lower calorific value of the fuel and the combustion efficiency respectively. $T_{4 i}$ relates with the pressure ratio across the turbine as,

$\left.T_{4 i}=T_{3}\left(r_{p}\right)^{\prime}\right)^{1-\gamma_{g}}$

where $r_{p}{ }^{\prime}$ is the pressure ratio across the turbine while $\gamma_{g}$ is the ratio of specific heat capacity of the flue gases, $\gamma_{g}$ is taken as 1.33 [20]. The pressure ratio is expressed as,

$r_{p}{ }^{\prime}=\frac{p_{3}}{p_{4}}$

There is pressure drop in the CC, also, there is pressure drop in the expansion process. Thus, $p_{3}$ and $p_{4}$ are obtained respectively by Equations (9) and (10),

$$
\begin{aligned}
& p_{3}=p_{2}\left(1-\frac{\Delta P_{C C}}{100}\right) \\
& p_{4}=p_{1}\left(1+\frac{\Delta P_{E x}}{100}\right)
\end{aligned}
$$

where $\Delta P_{C C}$ is the percentage drop in pressure in the $\mathrm{CC}$ while $\Delta P_{E x}$ is the percentage exhaust pressure drop. $T_{4 a}$ and $T_{4 i}$ are related as,

$$
T_{4 a}=T_{3}-\eta_{t i}\left(T_{3}-T_{4 i}\right)
$$

From the above, both the net work output and the turbine exit temperature depend on the five efficiency parameters. This can be expressed as,

$$
\dot{W}_{n e t} \& T_{4 a}=f\left(\text { Input }, \eta_{c i}, \eta_{t i}, \eta_{c c}, \Delta P_{C C}, \Delta P_{E x}\right)
$$

where Input refers to other input data such as air flow rate, fuel flow rate, pressure ratio, etc.

\subsection{Search Algorithm for the Determination of Efficiency Parameters}

For different values of the efficiency parameters, the net work output and the turbine exit temperatures can be computed and compared with the field values. The sum of the differences between the field and simulated values is expressed as in Equation (12),

$S=\left|\dot{W}_{n e t}-\dot{W}_{n e t, f}\right|+\left|T_{4 a}-T_{4 a, f}\right|$

where $\dot{W}_{n e t, f}$ and $T_{4 a, f}$ are the field values of the net work output and the turbine exit temperature respectively. The absolute values of the differences are added together. By generating several values of the efficiency parameters, the value of $S$ will be estimated. The set of the efficiency parameters that lead to the minimum value of $S$ are chosen as the adapted engine parameters. We can have $\mathrm{n}$ sets of each of the efficiency parameters:

$$
\begin{gathered}
\eta_{c i, i}, i=1,2, \ldots, n \\
\eta_{t i, i}, i=1,2, \ldots, n \\
\cdot \\
\Delta P_{E x, i}, 1,2, \ldots, n
\end{gathered}
$$

For $n$ sets of the five efficiency parameters, $n^{5}$ computations will be carried out, $n^{5}$ values of $S$ will be estimated and the combinations of the efficiency parameter where $S$ is minimum is thus sought. This involves long computation time and can only be carried out with the aid of computers. The higher the value of $\mathrm{n}$, the more the computation time, and the smaller will be the value of $S$ and hence the more accurate the adapted values.

\subsubsection{Selection of Range of Efficiency Parameters}

To create $\mathrm{n}$ sets of the efficiency parameters, the initial and the final values should enclose relevant values attributable to these parameters in practice. For instance, the combustion efficiency in practice is close to $100 \%$ [21], and this should serve as a guide in selecting the initial and the final 
combustion efficiency values for division into $\mathrm{n}$ places. The isentropic efficiencies of the compressor and the turbine are related to the pressure ratio as presented in Equations (13) and (14) [22],

$\eta_{c i}=1-\left(0.04+\frac{r_{p}-1}{150}\right)$

$\eta_{t i}=1-\left(0.03+\frac{r_{p}-1}{180}\right)$

The values of the isentropic efficiencies estimated from the above relations will guide us in selecting the range of values for simulation. Pressure loss in the $\mathrm{CC}$ for industrial turbines is usually around $1 \%$, but as much as $5 \%$ for Aeroderivative engines [23]. Exhaust pressure loss is usually lower. With the above, appropriate initial and final values for each efficiency parameter can be selected for simulations.

\subsection{Software Development for Adaptation}

The large numbers of computations required to obtain the adapted efficiency parameters necessitated the development of computer program to do the computations. Figure 2 shows the interface of the software developed in C\# programming environment where various input data can be provided.

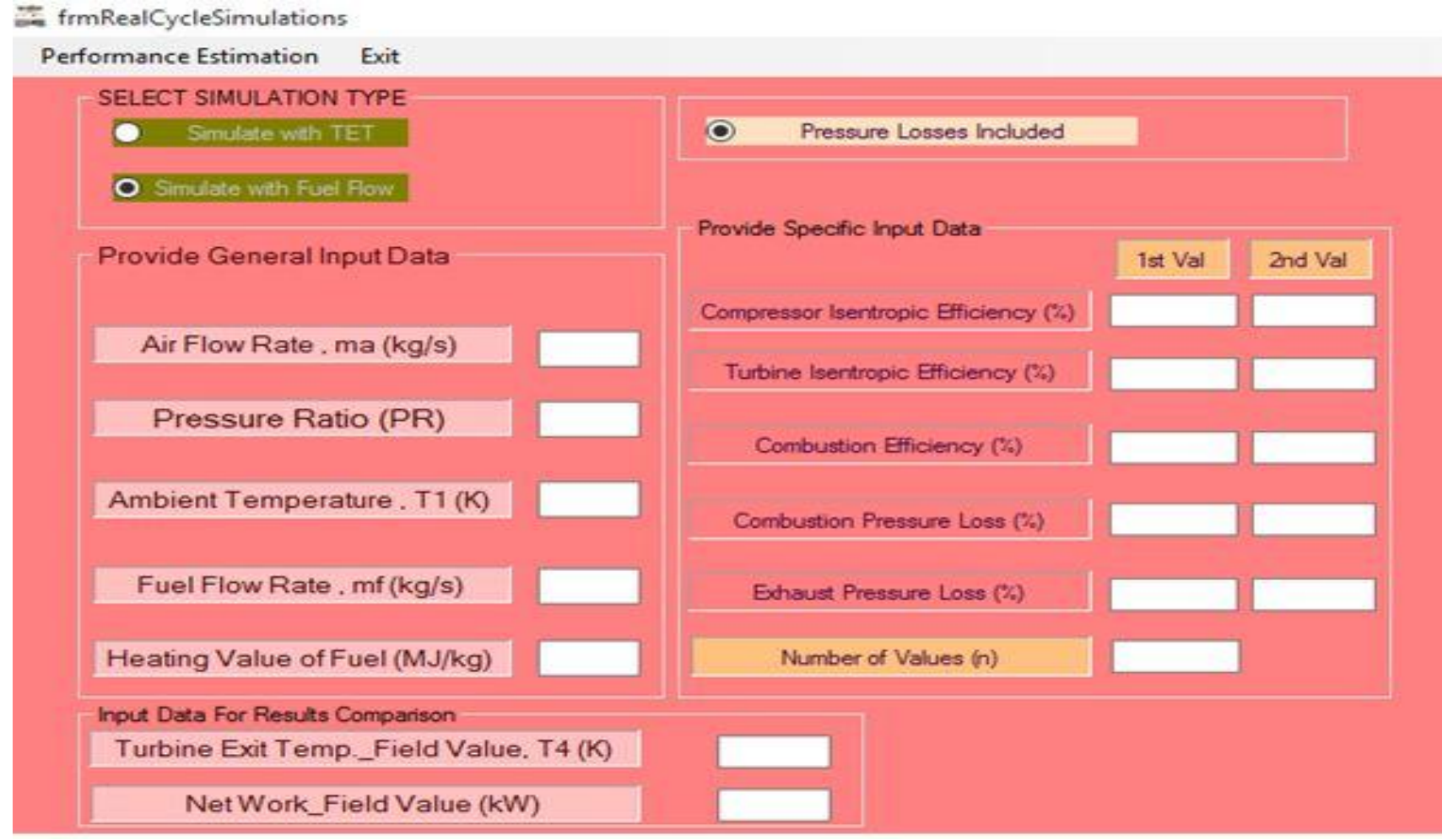

Fig 2: Program interface for data input for adaptation

\section{APPLICATIONS, RESULTS AND DISCUSSION}

The adaptation process developed in this work was applied to two gas turbine power plants in Rivers state, Nigeria.
Relevant input data for the adaptation of the two gas turbine plants is shown in Table 1. Figure 3 shows the interface with data inputted for power plat I. The same interface was used for inputting data for power plant II but with different input data.

Table 1. Input data for adaptation process for the two gas turbine plants

\begin{tabular}{lllll}
\hline \hline Items & Symbols & Units & $\begin{array}{l}\text { Values for } \\
\text { power plant I }\end{array}$ & $\begin{array}{l}\text { Values for } \\
\text { power plant II }\end{array}$ \\
\hline Mass flow rate of fuel & $\dot{\mathrm{m}}_{\mathrm{f}}$ & $\mathrm{kg} / \mathrm{s}$ & 3.65 & 1.98 \\
Mass flow of air & $\dot{\mathrm{m}}_{\mathrm{a}}$ & $\mathrm{kg} / \mathrm{s}$ & 247.2 & 124.1 \\
Lower heating values of fuel & $L C V_{f}$ & $M J / k g$ & 48.95 & 41.95 \\
Ambient air temperature & $\mathrm{T}_{0}$ & $\mathrm{~K}$ & 300 & 300 \\
Ambient air pressure & $\mathrm{P}_{0}$ & $\mathrm{kPa}$ & 101.325 & 101.325 \\
Exhaust Gas Temp & $\mathrm{T}_{4}$ & $\mathrm{~K}$ & 758 & 750 \\
Pressure ratio & $\mathrm{r}_{p}$ & - & 9.67 & 8.6 \\
Power Output & Wnet & $(\mathrm{kW})$ & 65000 & 26000 \\
\hline \hline
\end{tabular}


FrmRealCycleSimulations

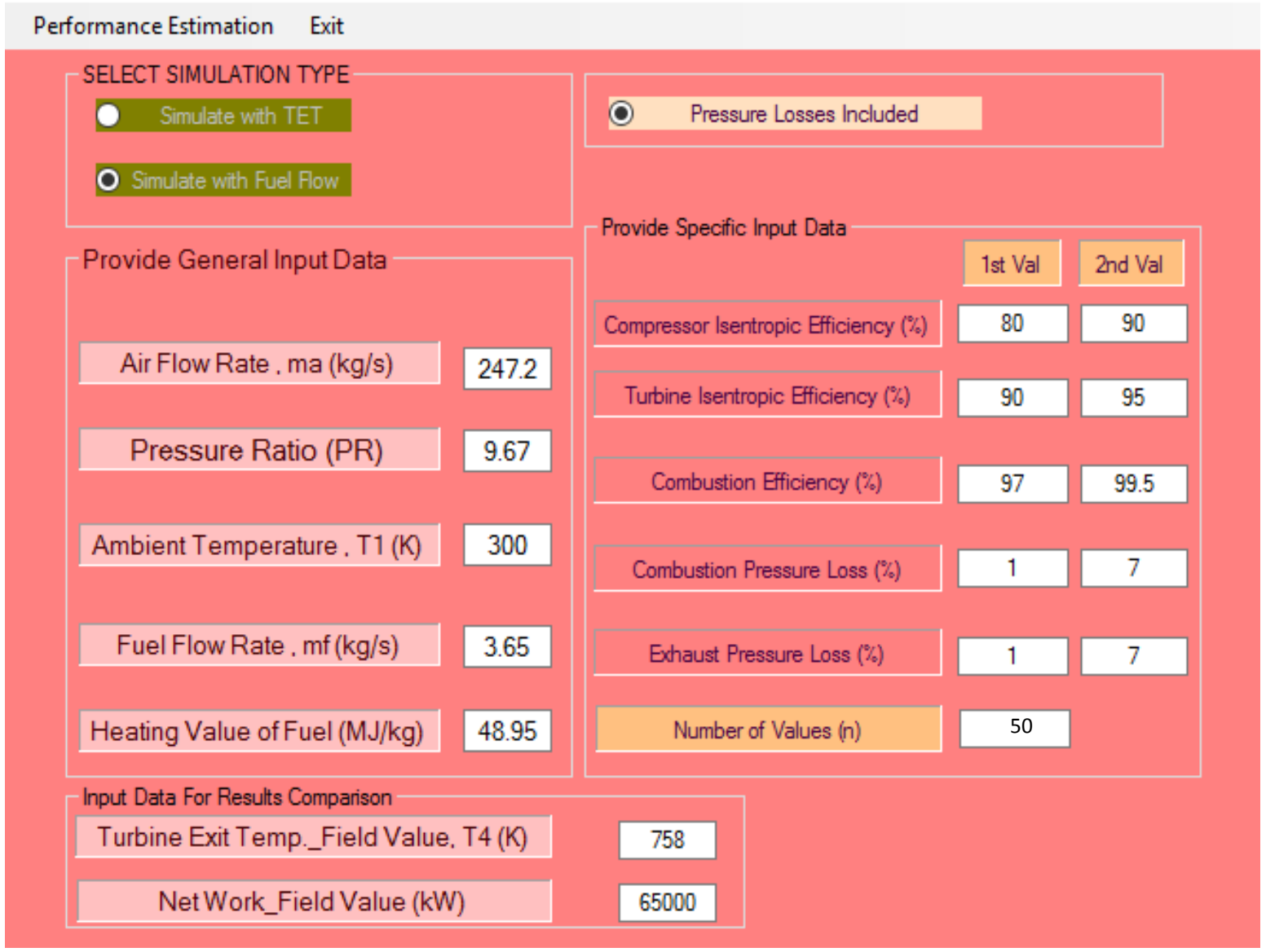

Fig3: Program interface with input data for power plant I

The efficiency parameters obtained for the two plants through adaptation are shown in Table 2. These parameters are selected in the adaptation process at the point the deviations of the net work output and the turbine exit temperature values from the simulations and those from the field are minimum. Table 3 shows the simulated results for power plant I compared with the field values while Table 4 shows the results for power plant II.

The net power output and the turbine exit temperature values obtained from the simulations closely matched those from the field, with the highest percentage difference between the two sets of values as low as $0.803 \%$ occurring for turbine exit temperature for power plant I. The power output values are closer for both power plants.

Table 5 shows similar results from a previous work where the efficiency parameters were estimated by manually varying them in a developed software. Comparing the results of Table 5 with those of Tables 3 and 4 showed that the adaptation process gave more accurate results.

Table 2. Efficiency parameters obtained from the adaptation for both power plants

\begin{tabular}{lcccc}
\hline \hline Parameter & Symbol & Unit & \multicolumn{2}{c}{ Value } \\
\cline { 5 - 5 } & & & Power plant I & Power plant II \\
\hline Compressor isentropic efficiency & $\eta_{\mathrm{c}, \mathrm{i}}$ & $\%$ & 87.78 & 82.44 \\
Turbine isentropic efficiency & $\eta_{\mathrm{t}, \mathrm{i}}$ & $\%$ & 93.89 & 91.11 \\
Combustion efficiency & $\eta_{\mathrm{cc}}$ & $\%$ & 99.22 & 98.67 \\
Combustion pressure loss & $\Delta \mathrm{P}_{\mathrm{cc}}$ & $\%$ & 5.67 & 2.33 \\
Exhaust pressure loss & $\Delta \mathrm{P}_{\mathrm{ex}}$ & $\%$ & 5.00 & 4.78 \\
\hline \hline
\end{tabular}


Table 3. Field data and simulated results for power plant I

\begin{tabular}{llllll}
\hline NO. & Parameter & Unit & Field value & Simulated value & Percentage difference \\
\hline 1 & Net Power Output & $\mathrm{kW}$ & 65000 & 65006.05 & 0.009 \\
2 & Exhaust gas temperature & $\mathrm{K}$ & 758 & 751.91 & 0.803 \\
\hline
\end{tabular}

Table 4. Field data and simulated results for power plant II

\begin{tabular}{llllll}
\hline NO. & Parameter & Unit & Field value & Simulated value & Percentage difference \\
\hline 1 & Net Power Output & $\mathrm{kW}$ & 26000 & 26001.38 & 0.005 \\
2 & Exhaust gas temperature & $\mathrm{K}$ & 750 & 748.62 & 0.184 \\
\hline
\end{tabular}

Table 5. Simulated results from previous for comparison [24]

\begin{tabular}{|c|c|c|c|c|c|c|c|}
\hline \multirow[t]{3}{*}{ NO. } & \multirow[t]{3}{*}{ Parameter } & \multirow[t]{3}{*}{ Unit } & \multirow{3}{*}{$\begin{array}{l}\text { Field } \\
\text { Data }\end{array}$} & \multicolumn{4}{|c|}{ Simulated Results } \\
\hline & & & & \multirow[t]{2}{*}{ Ideal Cycle } & \multicolumn{3}{|c|}{$\begin{array}{r}\text { Real Cycle } \\
\end{array}$} \\
\hline & & & & & CASE I & CASE II & CASE III \\
\hline 1 & Net Power Output & MW & 21.05 & 38.89 & 29.32 & 23.82 & 22.02 \\
\hline 2 & Exhaust gas temperature & $\mathrm{K}$ & 783 & 710.37 & 806.88 & 762.02 & 780.18 \\
\hline
\end{tabular}

\section{CONCLUSIONS}

A search algorithm was developed together with software to carry out gas turbine adaptation by estimating five efficiency parameters. Field data was collected from two power plants for the analysis and comparison with simulated results from the software. The turbine exit temperature and the net power output were selected for comparison. Both parameters from the simulations are very close to those obtained from the field for both power plants. The net power output values from the field are closer to those from the simulations for both plants compared to how the turbine exit temperature values from the field match those from the simulations. The adaptation process using a search algorithm gave more accurate results compared to the results of a previous study where the efficiency parameters were manually varied.

\section{ACKNOWLEDGMENTS}

Many thanks are due to the Department of Mechanical Engineering, University for providing the requisite environment for carrying out this work.

\section{REFERENCES}

[1] E. Saturday and J. C. Ofodu, "Development and Application of Gas Turbine Performance Analysis Software: Part 1- Ideal Cycles and Real Cycles",. International Journal of Computer Applications, vol.180, no.37, pp.20-26, 2018.

[2] V. Gutakovskis and V. Gudakovskis, "Adaptation of a Promising Gas Turbine Engine as the Main Approach to Improving its Performance" In: Transport Means 2019: Sustainability: Research and Solutions: Proceedings of the 23rd International Scientific Conference. Part 3, Lithuania, Palanga, 2-4 October, 2019. Kaunas: Kaunas University of Technology, pp.1370-1376, 2019.

[3] J. Sinai, C. Sugarmen and U. Fisher, "Adaptation and Modification of Gas Turbines for Solar Energy Applications", Proceedings of GT2005, ASME Turbo Expo 2005: Power for Land, Sea and Air June 6-9, 2005, Reno-Tahoe, Nevada, USA, 2005.

[4] U. Fisher, C. Sugarmen, A. Ring and J. Sinai, "Gas Turbine Solarization -Modifications for Solar/Fuel Hybrid Operation", Journal of Solar Energy Engineering,vol.126, no. 3, pp. 872-878, 2004.
[5] Y. G. Li, P. Pilidis, and M. A. Newby, "An Adaptation Approach for Gas Turbine Design-Point Performance Simulation”, J. Eng. Gas Turbines Power, vol. 128, no. 4, pp. 789-795, 2006.

[6] A. Stamatis, K. Mathioudakis and K. D. Papailiou, "Adaptive Simulation of Gas Turbine Performance," J. Eng. Gas Turbines Power, vol. 112, no. 2, pp. 168-175, 1990.

[7] B. R. Roth, D. L. Doel, D. Mavris and D. Beeson, "High Accuracy Matching of Engine Performance Models to Test Data", ASME Conf. Proc., (36843), Paper no. GT2003-38784, pp.129-137, 2003.

[8] B.R. Roth, D. Mavris, D. L. Doel, and D. Beeson, "High-accuracy Matching of Engine Performance Models to Test Data", American Society of Mechanical Engineers Paper GT2003-38784. 16, pp.1-10, 2004.

[9] Y.G. Li, "Gas Turbine Performance and Health Status Estimation Using Adaptive Gas Path Analysis", Journal of Engineering for Gas Turbines and Power, vol. 132, pp.1-9, 2020.

[10] Y. G. Li, M. Abdul Ghafir, L. Wang, R. Singh, K. Huang, and X. Feng, "Non - Linear Multiple Point Gas Turbine Off-Design Performance Adaptation Using a Genetic Algorithm", J. Eng. Gas Turbine Power,vol. 133, no. 7, pp.1-9, 2011.

[11] Y.G. Li, L. Marinai, V. Pachidis, E. Lo Gatto. and P. Pilidis, "Multiple-Point Adaptive Performance Simulation Tuned to Aeroengine Test-Bed Data", $J$. Propuls. Power, vol. 25, no. 3, pp. 635-641, 2009.

[12] Y.G. Li, M. F, Abdul- Ghafir, L. Wang, R. Singh, K. Huang and X. Feng, "Nonlinear Multiple Points Gas Turbine Off-Design Performance Adaptation Using a Genetic Algorithm", J. Eng. Gas Turbines Power, vol. 133, pp. 1-9, 2011.

[13] Y.G. Li, M. F. Abdul-Ghafir, L. Wang, R. Singh, K. Huang, X. Feng and W. Zhang, "Improved Multiple Point Nonlinear Genetic Algorithm Based Performance Adaptation Using Least Square Method," J. Eng. Gas Turbines Power, vol. 134, pp. 1-9, 2012.

[14] S. Kim, K. Kim and C. Son, "A new Transient 
Performance Adaptation Method for an Aero Gas Turbine Engine”, Energy, vol. 193, 2020.

[15] S. Kim, K. Kim and C. Son, "Adaptation Method for Overall and Local Performances of Gas Turbine Engine Model", International Journal of Aeronautical and Space Sciences, vol. 19, pp. 250-261, 2018.

[16] E. Tsoutsanis, Y. G. Li , P. Pilidis and M. Newby, “ Non-linear Model Calibration for Off-Design Performance Prediction of Gas Turbines with Experimental Data", International Society of Airbreathing Engines (ISABE) 2017 Conference, Manchester, 18 September 2017,Cambridge University Press.

[17] Y. G. Li, and R. Singh, "An Advanced Gas Turbine Gas Path Diagnostic System-PYTHIA", in The XVII International Symposium on Air Breathing Engines, Munich, Germany, 2005, pp. 1-12, 2005.

[18] E. G. Saturday and P. Nweke, "Off-Design Performance Analysis of Gas Turbines", Global Journal of Engineering and Technology Advances, vol. 4, no. 2, 0110,2020 .
[19] E. G. Saturday and O. A. E. Orok, "Comparative Exergo-Environmental Analysis of Simple and Regenerative Cycle Gas Turbine Plants", Scholars Journal of Engineering and Technology (SJET), vol. 6, no. 12, pp. 432-443, 2018.

[20] H. I. H. Saravanamuttoo, G. F. C. Rogers, H. Cohen, and P. V. Straznicky, Gas Turbine Theory, 6th ed. London: Pearson Educational Limited, 2009.

[21] A. H. Lefebvre, Gas Turbine Combustion, 2nd ed. Phiadelphia: Taylor and Francis, 1999

[22] M. M. Alhazmy and Y. S. H. Najjar, "Augmentation of Gas Turbine Performance Using Air Coolers", Appl. Therm. Eng., vol. 24, pp. 415-429, 2004.

[23] A. M. Y. Razak, Industrial Gas Turbines: Performance and Operability. Boca Raton, FL: Woodhead Publishing Limited, 2007.

[24] E. G. Saturday and J. C. Ofodu, "Development and Application of Gas Turbine Performance Analysis Software: Part I- Ideal Cycles and Real Cycles", International Journal of Computer Applications, vol. 180, no. 37, pp. 20-26, 2018. 